\title{
ATENDIMENTO ODONTOLÓGICO À PACIENTES COM DEFICIÊNCIA MENTAL
}

Larissa Coelho PIRES; Tales SCHERER; Viviane GOMES; Helen Cristina LAZZARIN.

Pessoa portadora de deficiência é aquela que apresenta, em caráter permanente, perdas ou anormalidades de sua estrutura ou função psicológica, fisiológica, ou anatômica, que gerem incapacidade para o desempenho de atividades dentro do padrão considerado normal para o ser humano. Segundo o Instituto Brasileiro de Geografia e Estatística (IBGE), 24,5 milhões de pessoas, cerca de $14,5 \%$ da população brasileira, possui algum tipo de deficiência, sendo que $8,3 \%$ apresenta deficiência mental. $O$ paciente é considerado deficiente mental se este apresentar limitações em pelo menos duas habilidades adaptativas como comunicação, cuidado pessoal, habilidades acadêmicas, e entre outros. $O$ tratamento odontológico dessas pessoas necessita de um tempo menor nas sessões e um número maior delas, além de exigir muito mais paciência e dedicação do profissional, e também a colaboração dos familiares, pois dependendo do grau de deficiência mental a higienização será de total responsabilidade dos cuidadores. Para 0 tratamento desses pacientes existem alguns métodos que podem auxiliar 0 odontólogo na realização de um tratamento de qualidade, como por exemplo, contenção física, sedação e anestesia geral. Após o procedimento, se for necessário medicar o paciente, deve-se atentar aos fatores biológicos que influenciam a resposta farmacológica do organismo. 